\title{
DE TRUMAN A TRUMP: O ETHOS DE PRESIDENTES DOS ESTADOS UNIDOS DA AMÉRICA EM DISCURSOS NA ASSEMBLEIA GERAL DA ONU
}

\author{
FROM TRUMAN TO TRUMP: THE ETHOS OF PRESIDENTS OF THE UNITED STATES IN \\ SPEECHES AT UNITED NATIONS ORGANIZATION GENERAL ASSEMBLY
}

Érico Lima de Oliveira

Doutorando em Direito Internacional pela USP. Mestre em Ciências pela Universidade de São Paulo e em Direito Internacional pela University College London

Defensor Público Federal

Mariana Sebalhos Jorge

Doutoranda em Direito Internacional pela USP. Mestre em Direito Internacional pela Universidade Federal do Rio Grande do Sul (UFRGS)

\section{RESUMO}

O presente artigo visa analisar o ethos de presidentes dos Estados Unidos da América em discursos proferidos na Assembleia Geral da ONU, do presidente Harry Truman ao presidente Donald Trump. Em um primeiro momento será realizada uma análise da retórica na construçáo do ethos, visto como o caráter do orador, como a imagem que este transmite ao seu auditório. Dessa forma, a análise dos meios de persuasão, das características essenciais do orador e a existência de um ethos pré-discursivo e de um ethos discursivo, será fundamental para que, em um segundo momento, seja possível a análise do ethos dos presidentes estadunidenses. A retórica é uma importante ferramenta utilizada no direito internacional, por meio da qual os países estabelecem as suas relações, os seus interesses, e as suas negociaçôes no sistema internacional.

Palavras-chave: Retórica. Direito Internacional. Ethos. Persuasão.

\begin{abstract}
This article aims to analyze the ethos of presidents of the United States of America in speeches delivered at the UN General Assembly, from President Harry Truman to
\end{abstract}


President Donald Trump. At first, an analysis of the rhetoric in the construction of ethos will be performed, as the character of the speaker, as the image that it transmits to his audience. Thus, the analysis of the means of persuasion, of the essential characteristics of the speaker, and the existence of a pre-discursive ethos and a discursive ethos will be fundamental for a second analysis of the ethos of the American presidents. Rhetoric is an important tool used in international law, through which countries establish their relations, their interests, and their negotiations in the international system.

Keywords: Rhetoric. International Right. Ethos. Persuasion.

\section{SUMÁRIO}

INTRODUÇÃO. 1. A RETÓRICA E O DIREITO INTERNACIONAL: OS MEIOS DE PERSUASÃO. 1.1 Os meios de persuasão do auditório e as características do orador. 1.2 O ethos pré-discursivo e o ethos discursivo. 2. DETRUMANATRUMP: UMA ANÁLISE DE DISCURSOS PRESIDENCIAIS NA ORDEM INTERNACIONAL. 2.1 O ethos e o direito internacional. 2.2 Análise de discursos proferidos por presidentes norte-americanos na Assembleia Geral da ONU. CONSIDERAÇÓES FINAIS

\section{INTRODUÇÁO}

A retórica possui uma relação tênue com o direito internacional, uma vez que é por meio de pronunciamentos, de discursos, de declaraçóes que o sistema internacional flui ao longo dos anos. $\mathrm{O}$ presente artigo busca explorar esta relação existente entre a retórica e o direito internacional, a partir da análise do ethos de presidentes norte- americanos em discursos proferidos na Assembleia Geral da Organização das Naçóes Unidas (ONU).

Para tanto, o artigo será dividido em duas partes. A primeira parte destinadaaos elementos da retórica, como os meios de persuasão do auditório, as características do orador e a análise do ethos, tanto discursivo como pré-discursivo. Para que em uma segunda parte seja possível a análise dos discursos proferidos pelos presidentes norte- americanos na Assembleia Geral da ONU, do discurso do presidente Harry Truman até o discurso do presidente Donald Trump.

O método utilizado será o dedutivo, partindo de uma análise geral e teórica da retórica, até premissas particulares a partir da análise dos discursos proferidos efetivamente. $\mathrm{O}$ objetivo deste artigo é averiguar o ethos dos presidentes norte- americanos em discursos proferidos na Assembleia Geral da ONU. Estes discursos foram escolhidos tendo em vista a importância que possuem no cenário internacional. 
O ethos dos presidentes estadunidenses dificilmente será construído apenas com base no discurso, uma vez que há uma imagem prévia associada a cada um, sendo presente um ethos pré-discursivo expressivo.

\section{A RETÓRICA E O DIREITO INTERNACIONAL: OS MEIOS DE PERSUAÇÃO}

Nesta primeira parte do artigo, será efetuada uma análise teórica da retórica, a partir de importantes consideraçóes doutrinárias referente ao ethos, visto como a imagem que o orador transmite ao ouvinte e a confiança que este possui. Serão analisados, assim, os meios de persuasão utilizados pelo orador, bem como as suas principais características: a prudência, (phronesis), a virtude (aretè) e a benevolência (eúnoia).

Será analisada, ainda, a diferenciação existente entre o ethos pré-discursivo e o ethos discursivo, como aponta Maingueneau ${ }^{1}$. É importante explanar, desde já, que Aristóteles ${ }^{2}$ defendia que a confiança deveria ser resultado do discurso e não de uma opinião prévia do auditório sobre o carácter do orador, o que contraria a existência de um ethos prédiscursivo como aponta Maingueneau.

Esta análise é fundamental para compreender, em um segundo momento, o ethos dos presidentes dos Estados Unidos da América em discursos proferidos na Assembleia Geral da ONU.

\subsection{Os meios de persuasáo do auditório e as características do orador}

A retórica atua como importante ferramenta no direito internacional. Conforme Aristóteles, a retórica compreende "a capacidade de descobrir o que é adequado a cada caso com o fim de persuadir" meios de persuasão mais pertinentes a cada caso ${ }^{4}$.

É importante mencionar que, conforme Aristóteles, há três espécies de provas de persuasão, que correspondem aos meios de persuasão ${ }^{5}$ utilizados através da retórica pelo orador. $\mathrm{O}$ 2008. p. 15.

MAINGUENEAU, D. A propósito do ethos. In: MOTTA; SALGADO (Org.) Ethos discursivo,

2 ARISTÓTELES. Retórica. Lisboa: Imprensa Nacional Casa da Moeda, 2005. v. VIII. Tomo I. p. 96.

3 ARISTÓTELES. Retórica. Lisboa: Imprensa Nacional Casa da Moeda, 2005. v. VIII. Tomo I. p. 96.

4 Aristóteles afirma: "É também evidente que ela é útil e que a sua função não é persuadir mas discernir os meios de persuasão mais pertinentes a cada caso, tal como acontece em todas as outras artes; de facto, não é função da medicina dar saúde ao doente, mas avançar o mais rápido possível na direção da cura, pois também se pode cuidar bem dos que já não estão em condiçôes de recuperar a saúde". ARISTÓTELES. Retórica. Lisboa: Imprensa Nacional Casa da Moeda, 2005. v. VIII. Tomo I. p. 96.

Conforme Aristóteles: "As provas de persuasão fornecidas pelo discurso são de três espécies: umas residem no carácter moral do orador; outras, no modo como se dispóe o ouvinte; e outras, no próprio discurso, pelo que este demonstra ou parece demonstrar". ARISTÓTELES. Retórica. Lisboa: Imprensa Nacional Casa da Moeda, 2005. v. VIII. Tomo I. p. 96. 
primeiro meio de persuasão é aquele que engloba o caráter moral do orador, a partir da imagem que este transmite ao ouvinte e a confiança que possui (ethos). O segundo meio de persuasão mantém o foco no auditório e em suas emoções (pathos), e o terceiro meio é a persuasáo pelo argumento, a partir de um discurso bem construído (logos).

O foco deste trabalho será o primeiro meio de persuasão apresentado, baseado na pessoa do orador, em que a persuasáo ocorre através do seu caráter, da sua confiança, credibilidade moral e científica. Conforme Aristóteles, "persuade-se pelo caráter quando o discurso é

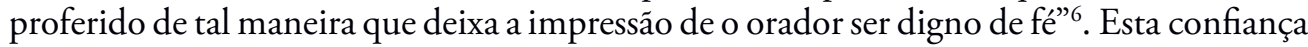
deveria ser "resultado do discurso e não de uma opinião prévia sobre o caráter do orador", entendendo que "não se deve considerar sem importância para a persuasão a probidade do que fala, como aliás alguns autores desta arte propóem, mas quase se poderia dizer que o carácter é o principal meio de persuasão"7.

Neste sentido, destaca-se que o orador inspira confiança por três razóes ${ }^{8}$, conhecidas como as suas características: a prudência (phronesis), a virtude (aretè) e a benevolência (eúnoia). A falta de qualquer uma destas características pode representar a alteração da verdade feita pelo orador, de modo que na falta de prudência, o orador não será razoável; ou sendo razoável, poderá ser desonesto; ou sendo prudente e honesto, não é benevolente? .

A phrónesis representa o parecer ponderado, a areté representa o parecer sincero e a eúnoia representa a imagem agradável e a boa aparência do orador. Conforme Henriques, "a este conjunto de atributos dá-se o nome de ethos", por meio do qual o orador transmite uma imagem de credibilidade, ainda que não seja verdadeira, uma vez que o "discurso persuasório funda-se não no ser verdadeiro, mas no parecer verdadeiro" ${ }^{10}$. Destas três características do orador (prudência, virtude e benevolência), verifica-se que "o ethos aristotélico relaciona-se com o caráter de honestidade que o orador do discurso mostrará

\footnotetext{
Afirma ainda: "Pois acreditamos mais e bem mais depressa em pessoas honestas, em todas as coisas
em geral, mas sobretudo nas de que não há conhecimento exacto e que deixam margem para dúvida". ARISTÓTELES. Retórica. Lisboa: Imprensa Nacional Casa da Moeda, 2005. v. VIII. Tomo I. p. 96.

7 ARISTÓTELES. Retórica. Lisboa: Imprensa Nacional Casa da Moeda, 2005. v. VIII. Tomo I. p. 97.

$8 \quad$ Aristóteles afirma que os oradores “inspiram confiança por três razóes; as que efetivamente, à parte as demonstraçóes, determinam nossa crença: a prudência (phronesis), a virtude (aretè) e a benevolência (eunoia)". ARISTÓTELES. Retórica. Lisboa: Imprensa Nacional Casa da Moeda, 2005. v. VIII. Tomo I. p. 98.

$9 \quad$ Este é o raciocínio desenvolvido por Aristóteles: “Se, de fato, os oradores alteram a verdade sobre o que dizem enquanto falam ou aconselham, é por causa de todas essas coisas de uma só vez ou de uma dentre elas: ou bem, por falta de prudência, eles não são razoáveis; ou, sendo razoáveis, eles calam suas opinióes por desonestidade; ou, prudentes e honestos, não são benevolentes; é por isso que podem, mesmo conhecendo o melhor caminho a seguir, não o aconselhar”. ARISTÓTELES. Retórica. Lisboa: Imprensa Nacional Casa da Moeda, 2005. v. VIII. Tomo I. p. 98.

10 Conforme Henriques: "Estabelece, outrossim, os componentes básicos do orador/falante ou as características do orador: a phrónesis (o parecer ponderado), a areté (o parecer sincero) e a eúnoia (imagem agradável, a boa aparência). A este conjunto de atributos dá-se o nome de éthos. Com eles, o orador/falante deixa transparecer ao destinatário uma imagem de credibilidade, mesmo que não seja verdadeira: o discurso persuasório funda-se não no ser verdadeiro, mas no parecer verdadeiro" HENRIQUES, Antônio. Argumentação e discurso jurídico. São Paulo: Atlas, 2013. p. 92.
} 
para parecer digno de credibilidade, perante aos interlocutores"11.

No mesmo sentido, Barthes afirma que o ethos "são traços de caráter que o orador deve mostrar ao auditório (pouco importa a sua sinceridade) para dar boa impressão", a partir de uma psicologia imaginária: "devo significar o que quero ser para o outro" 12 .

O objetivo do orador é, justamente, persuadir o auditório a incorporar o seu ethos ${ }^{13}$. Ainda que a retórica tradicional tenha relacionado o ethos à eloquência, à oralidade em fala pública, Dominique Maingueneau afirma que é preferível alargar o alcance do ethos, englobando "todos os tipos de texto, tanto os orais como os escritos" ${ }^{14}$. O texto escrito também possui "uma vocalidade que pode se manifestar numa multiplicidade de tons" 15 .

É possível distinguir, ainda, o ethos discursivo de um ethos pré-discursivo, como defende Dominique Maingueneau. Dificilmente a confiança do orador não sofrerá interferência da imagem prévia que o auditório possui, quando se estiver diante de uma figura pública conhecida, tal como políticos. Esta é uma diferenciação da teoria de Aristóteles, uma vez que este entendia que a confiança deveria ser um resultado do discurso e não de uma opinião prévia.

\section{$1.2 \mathrm{O}$ ethos pré-discursivo e o ethos discursivo}

O conceito do ethos representa a busca da adesão do auditório a uma opinião, no que Antônio Henriques denomina de "gerador de persuasão"16. Conforme Declercq, a prova pelo ethos envolve tudo o que contribui para destinar a imagem do orador a um determinado auditório na sua enunciação discursiva, como o "tom de voz, fluxo da fala, escolha das palavras e dos argumentos, gestos, mímicas, olhar, postura, aparência" ${ }^{17}$.

$11 \quad$ FIORINDO, P. P. Ethos: um percurso da retórica à análise do discurso. Revista Pandora Brasil. Revista de humanidades e de criatividade filosófica e literária. n. 47. 2012. p. 4.

12 BARTHES, R. A aventura semiológica. Portugal: Ediçôes 70, 1987. p. 74.

13 Henriques afirma que "o conceito de éthos está associado, de modo especial, ao de face e ao do eu; ao seu caráter e corporalidade, à sua maneira de habitar determinado espaço, sempre com o objetivo de levar o auditório a incorporar o seu éthos que se mostra no rosto, no corpo, na gestualidade e que emerge da roupa, da composiçáo harmônica das peças dos vestuários" HENRIQUES, Antônio. Argumentaçáo e discurso jurídico. São Paulo: Atlas, 2013.p. 92.

14 MAINGUENEAU, D. A propósito do ethos. In: MOTTA; SALGADO (Org.) Ethos discursivo. São Paulo: Contexto, 2008. p. 19.

15 O autor afirma: "Todo texto escrito, mesmo que o negue, tem uma 'vocalidade' que pode se manifestar numa multiplicidade de 'tons', estando eles, por sua vez, associados a uma caracterização do corpo do enunciador (e, bem entendido, não do corpo do locutor extradiscursivo), a um 'fiador', construído pelo destinatário a partir de índices liberados na enunciação. $\mathrm{O}$ termo 'tom' tem a vantagem de valer tanto para o escrito como para o oral”. MAINGUENEAU, Dominique. A propósito do ethos. In: MOTTA; SALGADO (Org.) Ethos discursivo. São Paulo: Contexto, 2008. p. 18.

16 HENRIQUES, A. Argumentaçáo e discurso jurídico, 2013. p. 97.

17 DECLERCQ, G. L'art d'argumenter - Structures rhétoriques et littéraires, 1992. p. 48. 
Neste sentido, Dominique Maingueneau afirma que a prova pelo ethos "consiste em causar uma boa impressão pela forma como se constrói o discurso, a dar uma imagem de si capaz de convencer o auditório, ganhando sua confiança" ${ }^{18}$. No entanto, é preciso ressaltar que o ethos visado nem sempre é o ethos produzido, a depender do ponto de vista do locutor ou do destinatário ${ }^{19}$.

É preciso diferenciar, no entanto, a existência do ethos discursivo e do ethos pré- discursivo. Ainda que Aristóteles tenha afirmado que a confiança deve ser resultado do discurso e não de uma opiniāo prévia do auditório sobre o caráter do orador ${ }^{20}$, Maingueneau defende que náo é possível ignorar uma imagem prévia que o auditório possui de um determinado orador $^{21}$, principalmente quando este orador é pessoa pública, como políticos ou celebridades. E assim, fica visível a existência de um ethos pré- discursivo, uma vez que há uma imagem que antecede ao discurso daquele determinado orador que não pode ser ignorada. Ruth Amossy afirma que é preciso saber se o ethos é a imagem de si construída no discurso ou "um dado preexistente que se apoia na autoridade individual e institucional do orador (a reputação de sua família, seu estatuto social, o que se sabe de seu modo de vida etc.)" ${ }^{\prime 2}$.

Conforme Dominique Maingueneau, "o ethos está crucialmente ligado ao ato de enunciação, mas não se pode ignorar que o público constrói também representações do ethos do enunciador antes mesmo que ele fale" ${ }^{23}$. Neste sentido, Kelen Rodrigues afirma que o ethos "não tem como desvencilhar-se da enunciação, assim como também não tem como escapar de uma antecipação por parte do leitor, que faz uma representação do enunciador antes mesmo que ele enuncie" 24 .

\footnotetext{
18 MAINGUENEAU, D. A propósito do ethos. In: MOTTA; SALGADO (Org.) Ethos discursivo.
} São Paulo: Contexto, 2008. p. 13.

19 Conforme Maingueneau, "a noção de ethos remete a coisas muito diferentes conforme seja considerada do ponto de vista do locutor ou do destinatário: o ethos visado não é necessariamente o ethos produzido". Neste sentido, cita como exemplo: "um professor que queira passar uma imagem de sério pode ser percebido como monótono; um político que queira suscitar a imagem de um indivíduo aberto e simpático pode ser percebido como um demagogo. Os fracassos em matéria de ethos são moeda corrente". MAINGUENEAU, Dominique. A propósito do ethos. In: MOTTA; SALGADO (Org.) Ethos discursivo. São Paulo: Contexto, 2008. p. 16.

20 Aristóteles afirma: "É, porém, necessário que esta confiança seja resultado do discurso e não de uma opiniáo prévia sobre o carácter do orador; pois não se deve considerar sem importância para a persuasão a probidade do que fala, como aliás alguns autores desta arte propóem, mas quase se poderia dizer que o carácter é o principal meio de persuasão". ARISTÓTELES. Retórica. Lisboa: Imprensa Nacional Casa da Moeda, 2005. v. VIII. Tomo I. p. 96.

${ }^{21}$ MAINGUENEAU, D. A propósito do ethos. In: MOTTA; SALGADO (Org.) Ethos discursivo, 2008. p. 15.

22 AMOSSY, R. Da noção retórica de ethos à análise do discurso. In: AMOSSY, Ruth (Org.). Imagens de si no discurso. A construçáo do ethos, 2005. p. 17.

23 MAINGUENEAU, D. A propósito do ethos. In: MOTTA; SALGADO (Org.) Ethos discursivo, 2008. p. 15.

24 RODRIGUES, K. O Ethos discursivo: uma análise por meio de seus traços na personagem Lord Henry no romance The Picture of Dorian Gray, de Oscar Wilde. Revista (Con)textos Linguísticos, 2014, p. 141. 
Assim, quando se está diante de um texto de um autor desconhecido, não se espera que o destinatário disponha de representaçóes prévias do ethos do locutor, ao mesmo tempo em que quando se está diante de políticos como os presidentes estadunidenses, por exemplo, a maior parte dos locutores está "associada a um tipo de ethos não-discursivo que cada enunciação pode confirmar ou infirmar" 25 .

O ethos pré-discursivo, ou, como denomina Antônio Henriques, o ethos prévio, refere-se à imagem "preexistente do locutor constituído de traços eufóricos ou disfóricos conhecidos pelo auditório" 26 . Enquanto no ethos discursivo, o próprio discurso irá construir o ethos do orador, um ethos que "aflora à medida que se desenvolve o discurso" ${ }^{27}$. Conforme Maria Helena Pistori, o ethos surge do discurso e "expressa-se nas recorrências temáticas, figurativas, de nível de linguagem, de recursos argumentativos" ${ }^{28}$. Dominique Maingueneau afirma, ainda, que "a persuasão não se cria se o auditório não puder ver no orador um homem que tem o mesmo ethos que ele", de modo que "persuadir consistirá em fazer passar pelo discurso um ethos característico do auditório, para lhe dar a impressão de que é um dos seus que ali está” 29 .

É importante compreender as características do orador e a construção do discurso a partir do ethos, para que seja possível analisar os discursos proferidos em Assembleias Gerais da ONU, por presidentes dos Estados Unidos da América em diferentes momentos históricos. Os presidentes norte-americanos são figuras públicas e de elevada importância para o direito internacional, de modo que é difícil pensar em um ethos tal qual propôs Aristóteles.

Há uma imagem preexistente associada a estes presidentes, de modo que não é possível ignorar as informaçôes prévias que o auditório possui, e o momento histórico existente em cada discurso. Neste sentido, Helena Brandão afirma que a "fala é recorte das representaçóes de um tempo histórico e de um espaço social", de modo que ao ser "projetado num espaço e num tempo orientado socialmente, o sujeito situa o seu discurso em relação aos discursos dos outros" ${ }^{\prime 3}$.

\footnotetext{
2008. p. 16.

MAINGUENEAU, D. A propósito do ethos. In: MOTTA; SALGADO (Org.) Ethos discursivo, 26 HENRIQUES, A.. Argumentação e discurso jurídico, 2013. p. 171.

28 Conforme a autora, "a gramática é o alicerce da cultura do orador, dando-lhe o domínio de seu instrumento privilegiado - o idioma, para que desempenhe bem seu papel. A preocupaçáo pragmática justifica-se pelo fato de que se cobram do orador aquelas qualidades". PISTORI, Maria Helena Cruz. A formação linguístico-discursiva do profissional da área jurídica. Revista do GEL, v. 3, 2006. p. 29.

29 MAINGUENEAU, D. A propósito do ethos. In: MOTTA; SALGADO (Org.) Ethos discursivo, 2008. p. 15.

30 Conforme a autora, "sua fala é produzida a partir de um determinado lugar e de um determinado tempo, à concepção de um sujeito histórico articulasse outra noção fundamental: a de sujeito ideológico". BRANDÃO, Helena H. Negamine. Introduçáo à análise do discurso. 3 ed. São Paulo: Editora da Unicamp, 2012. p. 59.
} 


\section{DE TRUMAN A TRUMP: UMA ANÁLISE DE DISCURSOS PRESIDENCIAIS NA ORDEM INTERNACIONAL}

Esta segunda parte do artigo pretende analisar o ethos em discursos proferidos por presidentes dos Estados Unidos da América ao longo dos anos, na Assembleia Geral da ONU. É importante perceber que cada presidente possuirá um perfil, com suas particularidades. Serão oradores com posturas diferentes, e com posturas que se justificam a partir do cenário político existente em cada momento histórico específico.

\subsection{O ethos e o direito internacional}

A capacidade de descobrir o que é adequado a cada caso com o fim de persuadir deve se fazer presente (ou deveria) nas palavras de um chefe de Estado, quando este se dirige a uma audiência global.

A Organização das Nações Unidas (ONU) foi criada após a Segunda Guerra Mundial, grande marco das relaçóes internacionais, para, dentre outros propósitos, desenvolver relaçôes entre as naçóes, baseadas no respeito ao princípio da igualdade de direitos e da autodeterminação dos povos, e tomar outras medidas apropriadas ao fortalecimento da paz universal conforme artigo $1^{\circ}$, item 2 , da sua carta constitutiva assinada em São Francisco, a 26 de junho de 1945, após o término da Conferência das Naçóes Unidas sobre Organização Internacional, entrando em vigor a 24 de outubro daquele mesmo ano.

Estabelecida a estrutura da Organização, observa-se, a partir de previsão do artigo $9^{\circ}$ da Carta, a criação de um foro multilateral para que todos os membros pudessem ter assento, que é a Assembleia Geral, "órgão plenário das Naçôes Unidas e o único órgão principal composto de todos os membros" ${ }^{31}$. Conforme artigo $20^{\circ}$ da Carta, a Assembleia Geral se reúne em sessôes anuais regulares ou em sessóes especiais. Ao longo do tempo percebese que a retórica usada pelos Chefes de Estado visava atingir o público para as questôes internacionais ali debatidas.

$31 \quad$ AKANDE, Dapo in EVANS, Malcolm. (ed.) International Law 2a ed. New York: OUP, 2006, p. 300. Tradução livre: "The General Assembly is the plenary organ of the United Nations and is the only principal organ composed of all member States". 
Uma pesquisa realizada pela base de dados online "Factba.se"32 compilou os discursos de Donald Trump, atual presidente dos Estados Unidos da América, e o comparou com discursos dos quatorze presidentes que o antecederam, a fim de determinar o grau de escolaridade Flesh-Kincaid ${ }^{33}$. O resultado abaixo foi encontrado.

\section{Flesch-Kincaid Grade Level}

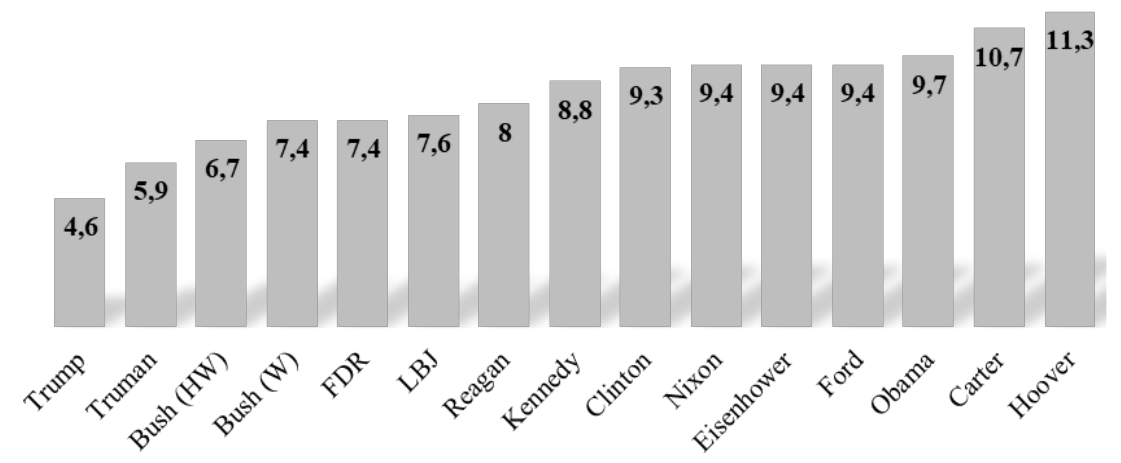

Fonte: Factba.se Disponível em: <https://blog.factba.se/2018/01/08/stable-genius-lets-go-to-the-data/> Acesso em: 21 nov. 2018.

Entre os resultados, observa-se que o discurso de Donald Trump, atual presidente dos Estados Unidos da América, possui o vocabulário mais básico quando comparado aos presidentes que o antecederam. Conforme o resultado encontrado na pesquisa, o nível de escolaridade para compreensão do discurso de Donald Trump é o menor exigido entre todos os presidentes comparados. A partir da retórica é possível compreender que este vocabulário simplista, visível nos discursos de Donald Trump, pode encontrar justifica no seu planejamento político, moldando o discurso ao auditório que este pretende alcançar, persuadir.

Serão analisados, aqui, os discursos dos seguintes presidentes: Harry Truman (19451953); John Kennedy (1961-1963); Richard Nixon (1969-1974); Jimmy Carter (19771981); Ronald Reagan (1981-1989); Bill Clinton (1993-2001); George W. Bush (20012009); Barack Obama (2009-2017); Donald Trump (2017-atualidade).

\footnotetext{
32 Fonte: Factba.se Disponível em: <https://blog.factba.se/2018/01/08/stable-genius-lets-go-to-the- data/> Acesso em: 21 nov. 2018.

33 Conforme José Roberto Goldim: "A legibilidade dos Termos de Consentimento Informados pode ser medida utilizando-se dois índices: o Índice de Legilibilidade de Flesh-Kinkaid e o de Facilidade de Leitura de Flesh. Ambos se baseiam no comprimento das palavras e frases do texto. [...]O resultado obtido com a fórmula estima os anos de estudo necessários para que o texto seja adequadamente compreendido. Os valores do Índice de Legibilidade de Flesh-Kincaid considerados mais efetivos para um texto são os que se situam entre 6 e 10". GOLDIM, José Roberto. Índices de Legibilidade de Flesch-Kincaid e de Facilidade de Leitura de Flesch. Disponível em: <https://www.ufrgs.br/bioetica/ilfk.htm> Acesso em: 21 nov. 2018.
} 
Todos os discursos analisados foram proferidos na Assembleia Geral da ONU, com exceção do presidente John Kennedy em que será analisado trecho do seu discurso de posse, em 1961. Entre os discursos proferidos na Assembleia Geral da ONU, o primeiro será o do presidente Harry Truman proferido em 1946. Seráo analisados ainda trechos dos discursos de Richard Nixon (1969), Jimmy Carter (1977); Ronald Reagan (1981); Bill Clinton (1993); George W. Bush (2001); Barack Obama (2011); e Donald Trump (2018).

Como será visto, cada presidente transpassa em seus discursos posturas adotadas nos seus governos, influenciadas pela política externa desenvolvida no período ${ }^{34}$. Conforme Paulo Borba Casella, "o discurso do direito internacional não pode ser compreendido sem relação com o tempo no qual este se formula", "como tampouco sem que se considere o contexto cultural do qual emerge a formulação" ${ }^{35}$. Entre os presidentes estadunidenses, por vezes, será visível uma postura calcada na proteção dos direitos humanos que se aproxima ao multilateralismo, e, em outros momentos, um discurso mais nacionalista, exaltando a América e os cidadãos americanos, aproximando-se de um isolacionismo.

\subsection{Análise de discursos proferidos por presidentes norte-americanos na Assembleia Geral da ONU}

Observa-se que quando Harry Truman (primeiro presidente do pós-guerra a falar na Assembleia Geral) proferiu seu discurso em 1946, o mundo saía de um dos mais violentos conflitos bélicos da história e tentava se reconstruir. Neste cenário, Truman evocou a assinatura da Carta como elemento constitutivo da Organizaçáo, fazendo referências ao passado isolacionista dos Estados Unidos da América, mencionando que naquele momento o seu Estado náo apenas era um membro, mas era a sede da $\mathrm{ONU}$, demonstrando a diferença da sua política externa. Truman fez, ainda, um alerta para que todos as naçóes fossem aliadas em torno de uma paz duradoura:

Recordo com grande prazer a última ocasião em que me encontrei e falei com os representantes das Naçóes Unidas. Muitos de vocês que estão aqui hoje estavam presentes então. Foi o último dia da conferência em San Francisco, quando a Carta das Naçóes Unidas foi assinada. Naquele dia a fundação constitucional das Naçóes Unidas foi colocada. Para o povo do meu país, esta reuniáo de hoje tem um

\footnotetext{
$34 \quad$ Lineide Salvador Mosca afirma: "Não se pode também deixar de considerar que cada época faz a leitura dos fatos deacordo com o seu próprio modo depensar, uma vezque eles comportam além daquilo que é dado, a maneira de os interpretar e de os comunicar. Cabe lembrar que quando se trata de signos, à diferença dos índices, há que contar com a questão da intencionalidade e evocar traços como os de polivalência, ambiguidade e imperfeição da linguagem em suas limitaçóes". SALVADOR MOSCA, Lineide. Velhas e novas retóricas: convergências e desdobramentos. In: SALVADOR MOSCA, Lineide(Org.). Retóricas deontem edehoje. São Paulo: Editora Humanitas, 2010.p. 19.

35 CASELLA, P. B. Tempo e discurso no direito internacional. In: CASELLA, Paulo Borba. Direito internacional no tempo antigo, 2012. p. 90.
} 
significado histórico especial. Depois da primeira guerra mundial, os Estados Unidos se recusaram a entrar para a Liga das Naçóes e nosso assento estava vazio na primeira reunião da Assembleia da Liga. Desta vez, Estados Unidos não é apenas um membro; é o anfitrião das Naçôes Unidas. Esta reunião da Assembleia simboliza o abandono pelos Estados Unidos de uma política de isolamento. A esmagadora maioria do povo americano, independentemente do partido, apoia as Naçóes Unidas. No entanto, devo dizer-lhe que o povo americano está preocupado com o fracasso das naçôes aliadas para fazer mais progressos em sua busca comum por uma paz duradoura. ${ }^{36}$

É importante mencionar que, quando Harry Truman assumiu a presidência dos Estados Unidos da América, o mundo ainda não estava profundamente dividido em dois grandes blocos, tendo em vista que americanos e soviéticos lutavam contra inimigo comum. No entanto, ao final de sua presidência o mundo já estava ciente da Guerra Fria que viria a ser o centro das relaçóes internacionais pelos próximos anos. Neste cenário, John Kennedy conclama as naçôes aliadas dos EUA, no seu discurso de posse em 1961, para permanecerem leais à influência americana:

E assim, meus compatriotas americanos, não perguntem o que seu país pode fazer por você, pergunte o que você pode fazer pelo seu país. Meus concidadáos do mundo, não perguntem o que a América fará por você, mas o que juntos podemos fazer pela liberdade do homem. ${ }^{37}$

John Kennedy, em seu discurso, dirige-se tanto aos cidadãos americanos, quanto aos cidadãos "do mundo", ainda que este não tenha sido proferido na Assembleia Geral da ONU. Diante de um cenário de Guerra Fria, o objetivo neste momento era reforçar a

\footnotetext{
$36 \quad$ Tradução livre de: "I recall with great pleasure the last occasion on which I met and spoke with the representatives of the United Nations. Many of you who are here today were present then. It was the final day of the Conference at San Francisco, when the United Nations Charter was signed. On that day the constitutional foundation of the United Nations was laid. For the people of my country this meeting today has a special historic significance. After the first world war the United States refused to join the League of Nations and our seat was empty at the first meeting of the League Assembly. This time the United States is not only a member; it is the host to the United Nations. This meeting of the Assembly symbolizes the abandonment by the United States of a policy of isolation. The overwhelming majority of the American people, regardless of party, support the United Nations. However, I must tell you that the American people are troubled by the failure of the Allied nations to make more progress in their common search for a lasting peace". Disponível em: <https://trumanlibrary.org/publicpapers/index.php?pid=914> Acesso em: 19 nov. 2018.

37 Tradução livre de: "And so, my fellow Americans, ask not what your country can do for you, ask what you can do for your country. My fellow citizens of the world, ask not what America will do for you, but what together we can do for the freedom of man". Disponível em: <https://www.americanrhetoric.com/ speeches/jfkinaugural.htm> Acesso em: 19 nov. 2018.
} 
importância do apoio dos aliados norte-americanos. A visão construída por Kennedy é de que apoiar os Estados Unidos da América representaria a busca pela liberdade do homem. Em 1969 observa-se o discurso do presidente Richard Nixon na Assembleia

Geral, em que este procurou estabelecer um apoio ao seu Estado na Guerra do Vietná, lembrando do papel de seu país no final da Segunda Guerra Mundial e procurando dividir a responsabilidade com a comunidade internacional por uma solução ao conflito que ainda se arrastaria por algum tempo e com consequências catastróficas para os Estados Unidos:

No final da Segunda Guerra Mundial, os Estados Unidos pela primeira vez na história assumiram a maior responsabilidade pela paz mundial. Fomos deixados em 1945 como a única nação com força suficiente para conter as novas ameaças de agressão, e com riqueza suficiente para ajudar as naçóes feridas a se levantarem. Para grande parte do mundo, aqueles primeiros anos difíceis do pós-guerra foram um período de dependência. Desde que assumi o cargo de presidente, nenhuma questão ocupou tanto do meu tempo e energia quanto a busca pelo fim da guerra no Vietná - um fim justo para o povo do Vietnã do Sul, justo para o povo do Vietná do Norte, e justo para aqueles outros que seriam afetados pelo resultado. Isso torna urgente que os membros da ONU, os que estáo nesta sala há muito tempo interessados na paz no Vietnã, agora tenham uma participação ativa para alcançá-lo. ${ }^{38}$

Passado o conflito no Vietná, o presidente Jimmy Carter fez questão de se aproximar da Organização das Naçóes Unidas, sendo a agenda de direitos humanos um grande tema da sua política externa. Deste modo, em 1977, Carter fez referências a assinatura e consequente aprovação dos Pactos Internacionais tanto de Direitos Civis e Políticos quanto dos Direitos Econômicos, Sociais e Culturais:

Eu vou buscar a aprovação do Congresso e assinar os pactos da ONU sobre direitos econômicos, sociais e culturais e os pactos sobre direitos civis e políticos. E vou trabalhar em estreita colaboração com

\footnotetext{
$38 \quad$ Tradução livre de: "At the end of World War II, the United States for the first time in history assumed the major responsibility for world peace. We were left in 1945 as the one nation with sufficient strength to contain the new threats of aggression, and with sufficient wealth to help the injured nations back to their feet. For much of the world, those first difficult postwar years were a time of dependency. Since I took office as President, no single question has occupied so much of my time and energy as the search for an end to the war in Vietnam -- an end fair to the people of South Vietnam, fair to the people of North Vietnam, and fair to those others who would be affected by the outcome. This makes it urgent that the U.N. members, those in this room who have long taken an active interest in peace in Vietnam, now take an active hand in achieving it." Disponível em: <https://www.americanrhetoric.com/speeches/richardnixonunitednations1969. htm> Acesso em: 19 nov. 2018.
} 
o nosso próprio Congresso na tentativa de apoiar a ratificação não apenas destes dois instrumentos, mas também da Convenção do Genocídio das Naçóes Unidas e do Tratado para a Eliminaçáo de Todas as Formas de Discriminação Racial. As Naçóes Unidas são um fórum global dedicado à paz e ao bem-estar de todos os indivíduos - não importa quão fracos sejam, não importa quão pobres sejam. Mas permitimos que sua máquina de direitos humanos seja ignorada e às vezes politizada. Há muito que pode ser feito para fortalecê-lo. ${ }^{39}$

Ronald Reagan a seu turno, em 1981, fez referências explícitas à força da Carta das Naçóes Unidas em um momento de corrida armamentista (citado pelos historiadores como Segunda Guerra Fria):

\begin{abstract}
Nós, que assinamos a Carta da ONU, nos comprometemos a evitar a ameaça ou o uso da força contra o território ou a independência de qualquer estado. Nestes tempos, quando mais e mais atos ilegais ficam impunes - como alguns membros deste mesmo corpo mostram um crescente desrespeito pela Carta da ONU - as naçóes amantes da paz do mundo devem condenar a agressáo e prometer novamente agir de uma forma que seja digno dos ideais que nós endossamos. Vamos finalmente dar vida à Carta. ${ }^{40}$
\end{abstract}

Finalmente, ao final da Guerra Fria, o mundo vivia uma grande fase de otimismo, a ordem internacional parecia responder a muitos problemas e a diplomacia seria o caminho para a solução das diferenças. Esta postura fica explícita no discurso de Bill Clinton na Assembleia Geral em 1993:

39 Tradução livre de: "I will seek congressional approval and sign the U.N. covenants on economic, social, and cultural rights, and the covenants on civil and political rights. And I will work closely with our own Congress in seeking to support the ratification not only of these two instruments but the United Nations Genocide Convention and the Treaty for the Elimination of All Forms of Racial Discrimination, as well. The United Nations is a global forum dedicated to the peace and well-being of every individual--no matter how weak, no matter how poor. But we have allowed its human rights machinery to be ignored and sometimes politicized. There is much that can be done to strengthen it". Disponível em: <https://millercenter.org/the-presidency/presidential-speeches/march-9-1977-remarks-president-carters- press-conference> Acesso em: 21 nov. 2018.

$40 \quad$ Tradução livre de: "We, who have signed the U.N. Charter, have pledged to refrain from the threat or use of force against the territory or independence of any state. In these times when more and more lawless acts are going unpunished - as some members of this very body show a growing disregard for the U.N. Charter-the peace-loving nations of the world must condemn aggression and pledge again to act in a way that is worthy of the ideals that we have endorsed. Let us finally make the charter live". Disponível em: <https:// www.reaganlibrary.gov/research/speeches/61782a > Acesso em: 21 nov. 2018. 
É claro que vivemos em um momento decisivo na história humana. Mudanças imensas e promissoras parecem nos inundar todos os dias. A guerra fria acabou. $\mathrm{O}$ mundo não está mais dividido em dois campos armados e furiosos. Dezenas de novas democracias nasceram. É um momento de milagres. Vemos Nelson Mandela lado a lado com o presidente de Klerk, proclamando uma data para a primeira eleição não-racial da África do Sul. Vemos o primeiro presidente eleito da Rússia, Boris Yeltsin, liderando sua nação em sua ousada jornada democrática. Vimos décadas de impasse no Oriente Médio, quando o primeiro-ministro de Israel e o presidente da Organizaçáo de Libertação da Palestina chegaram à inimizade do passado, e suspeitos de apertar as mãos uns dos outros e estimular o mundo inteiro com a esperança da paz. ${ }^{41}$

Esta realidade otimista não pôde ser vislumbrada por muito tempo. Em 11 de setembro de 2001 forças terroristas promoveram um dos maiores atentados que o mundo já conheceu nas cidades de Nova Iorque e Washington. O discurso do entáo presidente dos Estados Unidos da América, George W Bush, usou da retórica belicista para solicitar o apoio da comunidade internacional, inclusive da própria ONU, para a chamada "Guerra ao Terror" usando do argumento do inimigo comum:

Toda nação tem interesse nessa causa. Quando nos encontramos, os terroristas planejam mais assassinatos - talvez no meu país, ou talvez no seu. Eles matam porque aspiram dominar. Eles procuram derrubar governos e desestabilizar regióes em que a democracia nasceu. ${ }^{42}$

Já o presidente Barack Obama ao se dirigir às Nações Unidas faz referências ao passado e ao próprio discurso do presidente Truman, a fim de demonstrar que a América estaria se aproximando novamente do multilaterialismo e se afastando da Guerra ao Terror incentivada pelo presidente anterior:

\footnotetext{
$41 \quad$ Tradução livre de: "It is clear that we live at a turning point in human history. Immense and promising changes seem to wash over us every day. The cold war is over. The world is no longer divided into two armed and angry camps. Dozens of new democracies have been born. It is a moment of miracles. We see Nelson Mandela stand side by side with President de Klerk, proclaiming a date for South Africa's first nonracial election. We see Russia's first popularly elected President, Boris Yeltsin, leading his nation on its bold democratic journey. We have seen decades of deadlock shattered in the Middle East, as the Prime Minister of Israel and the Chairman of the Palestine Liberation Organization reached past enmity and suspicion to shake each other's hands and exhilarate the entire world with the hope of peace". Disponível em: <https://2009-2017. state.gov/p/io/potusunga/207375.htm> Acesso em: 19 nov. 2018.

42 Tradução livre de: "Every nation has a stake in this cause. As we meet, the terrorists are planning more murder - perhaps in my country, or perhaps in yours. They kill because they aspire to dominate. They seek to overthrow governments and destabilize entire regions democracies have been born". Disponível em: <http://edition.cnn.com/2001/US/11/10/ret.bush.un.transcript/index.html> Acesso em: 19 nov. 2018.
} 
Esta tem sido uma década difícil. Hoje, porém, estamos numa encruzilhada da história, com a chance de avançar decisivamente na direçáo da paz. Para fazer isso, devemos retornar à sabedoria daqueles que criaram esta instituição. A Carta Fundacional da ONU nos convida a "unir nossas forças para manter a paz e a segurança internacionais". E o Artigo 1 da Declaração Universal dos Direitos Humanos da Assembleia Geral nos lembra que "todos os seres humanos nascem livres e iguais em dignidade e direitos". Essas crenças fundamentais - na responsabilidade dos estados e nos direitos de homens e mulheres - devem ser o nosso guia. Quando a pedra angular deste mesmo edifício foi colocada em prática, o presidente Truman veio para Nova York e disse: "As Naçóes Unidas são essencialmente uma expressão da natureza moral das aspiraçóes do homem”. Como vivemos em um mundo que está mudando a um ritmo de tirar o fôlego, essa é uma liçáo que nunca devemos esquecer. A paz é dura, mas sabemos que isso é possível. Juntos, vamos resolver para ver que isso é definido por nossas esperanças e não por nossos medos. Juntos, vamos trabalhar para fazer, não apenas uma paz, mas uma paz que durará. Obrigado. ${ }^{43}$

O discurso proferido pelo presidente Barack Obama demonstra a postura adotada pelos Estados Unidos da América durante os seus dois mandatos, a partir de uma visão universalista. No entanto, com a chegada de Donald Trump à presidência fica nítida a mudança de tom. Donald Trump explicitou que a sua administração iria, em primeiro lugar, perseguir os interesses nacionais. Menciona, ainda, a saída dos Estados Unidos da América do Conselho de Direitos Humanos das Naçóes Unidas, e o não reconhecimento da jurisdição do Tribunal Penal Internacional. Estas açóes representam um turning point na política externa norte-americana tendo em vista sobretudo as presidências de Truman e Carter:

Como meu governo demonstrou, os EUA sempre agirão a partir do nosso interesse nacional. Eu falei com este órgão no ano passado

\footnotetext{
$43 \quad$ Tradução livre de: "This has been a difficult decade. But today, we stand at a crossroads of history with the chance to move decisively in the direction of peace. To do so, we must return to the wisdom of those who created this institution. The UN's Founding Charter calls upon us, "to unite our strength to maintain international peace and security." And Article 1 of this General Assembly's Universal Declaration of Human Rights reminds us that, "All human beings are born free and equal in dignity and rights.' Those bedrock beliefs - in the responsibility of states, and the rights of men and women - must be our guide. When the corner-stone of this very building was put in place, President Truman came here to New York and said, "The United Nations is essentially an expression of the moral nature of man's aspirations." As we live in a world that is changing at a breathtaking pace, that is a lesson that we must never forget. Peace is hard, but we know that it is possible. Together, let us resolve to see that it is defined by our hopes and not our fears. Together, let us work to make, not merely a peace, but a peace that will last. Thank you". Disponível em: <https:// foreignpolicy.com/2011/09/21/full-text-of-obamas-speech-at-the-united-nations> Acesso em: 19 nov. 2018.
} 
e avisei que o Conselho de Direitos Humanos da ONU se tornou um grave constrangimento para esta instituição, protegendo os abusadores dos direitos humanos e atacando os Estados Unidos e seus muitos amigos. Nossa Embaixadora nas Naçóes Unidas, Nikki Haley, estabeleceu uma agenda clara para a reforma, mas, apesar dos avisos relatados e repetidos, nenhuma ação foi tomada. Assim, os Estados Unidos adotaram o único caminho responsável: retiramo-nos do Conselho de Direitos Humanos e não retornaremos até que a verdadeira reforma seja promulgada. Por razóes semelhantes, os Estados Unidos não fornecerão apoio em reconhecimento ao Tribunal Penal Internacional. No que diz respeito à América, o TPI não tem jurisdição, legitimidade e autoridade. O TPI reivindica jurisdição quase universal sobre os cidadáos de todos os países, violando todos os princípios de justiça e devido processo legal. Jamais renderemos a soberania dos Estados Unidos a uma burocracia global não- eleita, inexplicável e governada por americanos. Rejeitamos a ideologia do globalismo e abraçamos a doutrina do patriotismo. ${ }^{44}$

Os trechos dos discursos aqui demonstrados revelam muito do tempo em que foram proferidos e do que os Estados Unidos da América esperavam da comunidade de naçóes. Como afirma Paulo Borba Casella, "o tempo - ou se diga, a história - e o lugar - ou se diga o contexto cultural - sempre terão impacto sobre o direito internacional, como ademais sobre todas as coisas produzidas pela inteligência humana, e como tais, humanamente condicionadas e contingentes" ${ }^{\prime 2}$.

Para que suas políticas fossem aprovadas em um foro multilateral como a da ONU, muitos usaram da retórica e algumas vezes foram bem sucedidos. No entanto, a retórica poderia embalar também situaçóes que nem sempre a comunidade internacional poderia tolerar, tais como o endosso à Guerra do Vietnã ou mesmo à chamada "Guerra ao Terror" demonstrando que, além da retórica, é necessário comparecer a um foro internacional calcado no próprio Direito Internacional, o que parece ser uma obviedade. Entretanto,

\footnotetext{
$44 \quad$ Tradução livre de: "As my administration has demonstrated, America will always act in our national interest. I spoke before this body last year and warned that the U.N. Human Rights Council had become a grave embarrassment to this institution, shielding egregious human rights abusers while bashing America and its many friends. Our Ambassador to the United Nations, Nikki Haley, laid out a clear agenda for reform, but despite reported and repeated warnings, no action at all was taken. So the United States took the only responsible course: We withdrew from the Human Rights Council, and we will not return until real reform is enacted. For similar reasons, the United States will provide no support in recognition to the International Criminal Court. As far as America is concerned, the ICC has no jurisdiction, no legitimacy, and no authority. The ICC claims near-universal jurisdiction over the citizens of every country, violating all principles of justice, fairness, and due process. We will never surrender America's sovereignty to an unelected, unaccountable, global bureaucracy America is governed by Americans. We reject the ideology of globalism, and we embrace the doctrine of patriotism". Disponível em: <https://www.whitehouse.gov/briefings-statements/remarks-president-trump-73rd-session-united-nations- general-assembly-new-york-ny/> Acesso em: 19 nov. 2018.

45 CASELLA, P. B. Tempo e discurso no direito internacional. In: CASELLA, P. B. Direito internacional no tempo antigo. São Paulo: Atlas, 2012. p. 131.
} 
pelos exemplos juntados no presente trabalho nem sempre se enxerga o óbvio.

\section{CONSIDERAÇÓES FINAIS}

Como visto, a retórica mantém uma relação próxima com o direito internacional. O presente artigo pretendeu explorar esta relação a partir da análise do ethos de presidentes norte-americanos em discursos proferidos na Assembleia Geral da Organizaçáo das Naçóes Unidas (ONU). Foram analisados trechos de discursos dos presidentes Harry Truman (1946); Richard Nixon (1969), Jimmy Carter (1977); Ronald Reagan (1982); Bill Clinton (1993); George W. Bush (2001); Barack Obama (2011); e Donald Trump (2018). Foi analisado, ainda, um trecho do discurso de posse do presidente John Kennedy, proferido em 1961.

Para tanto, o artigo foi dividido em duas partes. A primeira parte destinada aos elementos da retórica, como os meios de persuasão do auditório, as características do orador e a análise do ethos, tanto discursivo como pré-discursivo. E a segunda parte destinada à análise dos discursos proferidos pelos presidentes norte-americanos na Assembleia Geral da ONU, do discurso do presidente Harry Truman até o discurso do presidente Donald Trump.

É importante frisar que o ethos dos presidentes estadunidenses dificilmente será construído apenas com base no discurso tal como propôs Aristóteles, uma vez que há uma imagem prévia associada a cada um. Esta imagem prévia dita o impacto que cada discurso possui no auditório, estando-se diante de um significativo ethos pré-discursivo, tal como propôs Maingueneau. Os discursos analisados visam, justamente, persuadir o auditório a incorporar o ethos do orador. Visam persuadir os cidadáos estadunidenses de que as açóes políticas adotadas pelo presidente são as melhores entre as opções existentes, e persuadir os demais países a tornarem-se aliados.

Nestes casos, o discurso não se desvencilha da imagem prévia do orador, que interfere diretamente no ethos daquele que fala. Cada discurso, como visto, é proferido em concordância com açóes governamentais que moldam a política externa dos Estados Unidos da América em cada período correspondente. Há presidentes que permeiam o seu governo em açôes voltadas aos direitos humanos com uma política externa voltada ao multilateralismo, e há presidentes que exacerbam o nacionalismo a partir de uma política externa isolacionista. A retórica corresponde a uma ferramenta essencial na consagração da política externa de um país como os Estados Unidos da América, interferindo diretamente na ordem internacional. 


\section{REFERÊNCIAS}

AKANDE, D. In: EVANS, Malcolm. International Law 2a ed. New York: OUP, 2006, p. 300 .

AMOSSY, R. Da noção retórica de ethos à análise do discurso. In: AMOSSY, Ruth (Org.). Imagens de si no discurso. A construção do ethos. São Paulo: Contexto, 2005. p. 9-28.

ARISTÓTELES. Retórica. Lisboa: Imprensa Nacional Casa da Moeda, 2005. v. VIII. Tomo I.

BARTHES, R. A aventura semiológica. Portugal: Ediçōes 70, 1987.

BRANDÃO, H. H. N. Introduçáo à análise do discurso. 3 ed. São Paulo: Editora da Unicamp, 2012. p. 59.

CASELLA, P. B. Tempo e discurso no direito internacional. In: CASELLA, Paulo Borba. Direito internacional no tempo antigo. São Paulo: Atlas, 2012. p. 89-163.

DECLERCQ, G. L'art d'argumenter - Structures rhétoriques et littéraires. Paris: Editions Universitaires, 1992.

FIORINDO, Priscila Peixinho. Ethos: um percurso da retórica à análise do discurso. Revista Pandora Brasil. Revista de humanidades e de criatividade filosófica e literária. n. 47. 2012. p. 1-8.

HENRIQUES, A. Argumentaçáo e discurso jurídico. São Paulo: Atlas, 2013.

MAINGUENEAU, D. A propósito do ethos. In: MOTTA; SALGADO (Org.) Ethos discursivo. São Paulo: Contexto, 2008. p. 11-29.

PERELMAN, C. \& OLBRECHTS-TYTECA, L. Tratado da argumentaçáo. A nova retórica. 1. ed., 2. tiragem. São Paulo: Martins Fontes, 1996.

PERELMAN, C. Lógica jurídica. São Paulo: Martins Fontes, 1998.

PISTORI, M. H. C. A formação linguístico-discursiva do profissional da área jurídica. Revista do GEL, v. 3, 2006. p. 25-45.

QUINTILIANO. Institutio oratoria. Translated by H. E. Butler. Loeb Classical Library. London, Cambridge, Massachetts: Harvard University Press, 1996.

RODRIGUES, K. O Ethos discursivo: uma análise por meio de seus traços na personagem Lord Henry no romance The Picture of Dorian Gray, de Oscar Wilde. Revista (Con)textos Linguísticos, v. 8, n. 10, 2014. p. 139-158.

SALVADOR MOSCA, L. Velhas e novas retóricas: convergências e desdobramentos. In: SALVADOR MOSCA, Lineide (Org.). Retóricas de ontem e de hoje. São Paulo: Editora Humanitas, 2010. p. 17-54. 